Hubo consenso entre los participantes, sobre la necesidad de crear el Sistema Nacional de Información para el Sector Educativo, el cuál solucionaría en parte los problemas existentes con la información estadístico que se produce actualmente en el país. Las estadísticas que se han venido elaborando generalmente no prestan un servicio adecuado para la planeación, investigación y evaluación de la educación, debido básicamente, a la diversidad de objetivos, contenidos y criterios con que se elaboran ya que estas, obedecen a las necesidades e intereses de las entidades encargadas de producirlas. El resultado es la gran variedad de datos, en la mayoría de los casos diferentes lo cual impide que la información sea lo suficientemente confiable. Al crearse el sistema nacional de información educativa se tendrá un conocimiento amplio, de la educación en el país, lo cual servirá para la planeación y formulación de políticas para el sector, basadas en la comprensión de la educación las necesidades reales, y una racional utilización de los recursos disponibles, evitándose la duplicación de esfuerzos y costos.

Las recomendaciones formuladas por los participantes se centraron en aportar elementos para la elaboración del diseño del Sistema Nacional de Información, el cual deberá ser realizado conjuntamente por las entidades que actualmente elaboran las estadísticas educativas, y deberán contar con el apoyo de las autoridades que tienen la responsabilidad de definir las políticas del sector, como de las directivas de instituciones que lo integran a fin de que el sistema presentado se fundamente en normas legales que garanticen su establecimiento y continuidad.

Las conclusiones y recomendaciones planteadas serán publicadas por el Ministerio de Educación, a donde podrán acudir las personas interesadas.

Piedad Caballero Prieto

\title{
SEMINARIO-TALLER SOBRE DESARROLLO PSICOLINGUISTICO DEL NIÑO NORMAL Y DEL NIÑO CON DIFICULTADES DE DESARROLLO
}

Del 23 al 27 de abril tuvo lugar en la Universidad de los Andes el Seminario Taller sobre Desarrollo Psico-lingüístico del Niño Normal y del Niño con Dificultades de Desarrollo. Este evento fue organizado dentro del Programa de Investigaciones Sobre el Niño que adelanta la Universidad de los Andes, contó con los auspicios del Consejo Británico.

La dirección del seminario estuvo a cargo del Doctor Geoffrey P. Ivimey, de la Universidad de Londres, y la coordinación general a cargo de la Doctora Martha Luz de Londoño, de la Universidad de los Andes. Participaron especialistas en español, educación especial, educación preescolar, fonoaudiología, lenguas extranjeras, lingüística, matemáticas, pediatría y psicología, quienes trabajan en diferentes instituciones tanto oficiales como privadas.

Los temas centrales fueron:

— Procesos de la comunicación y de la información. 
-Metodología de la investigación psicológica y lingüística.

—Procesos de la adquisición normal del lenguaje.

—Análisis de la fonología.

—Desarrollo psicolingüístico de los niños sordos.

—Análisis de la sintaxis de los niños sordos.

—Desarrollo psicolingüístico de los niños con dificultades intelectuales y de los niños con desventaja social.

—Análisis de la sintaxis de una niña con retardo mental.

—Procesos de adquisición del lenguaje. Análisis comparativo de diferentes métodos.

—El problema de la adquisición de una segunda lengua en la niñez.

Los aspectos tratados suscitaron gran interés en los participantes. Si bien es cierto que en Colombia se han realizado investigaciones y numerosos estudios referentes a la educación del niño, son pocos los trabajos que se han adelantado sobre su desarrollo psicolingüístico en particular.

Por otra parte, se analizaron algunos aspectos del aprendizaje de lenguas extranjeras en relación con la adquisición del lenguaje por parte de niños sordos.

Este seminario-taller ha sido una valiosa oportunidad para el intercambio de ideas y de experiencias entre los participantes, quienes a través de sus diferentes actividades profesionales -investigación, docencia, administración de programas educativos y de bienestar social- contribuyen a la búsqueda y a la aplicación de soluciones en el complejo campo de la educación, ya sea ésta referida al niño normal o al niño con dificultades de desarrollo.

La importancia de este encuentro radica no solamente en los temas desarrollados, sino también, y especialmente, en las proyecciones que puede tener para el trabajo interdisciplinario e interinstitucional en el área de la investigación psicolingüística, elemento fundamental para el diseño y el desarrollo del currículo de la educación infantil. 